\title{
Pathophysiology and clinical characteristics of hypothalamic obesity in children and adolescents
}

\author{
Ja Hye Kim, MD, \\ Jin-Ho Choi, MD, PhD \\ Division of Pediatric Endocrinology \\ \& Metabolism, Department of \\ Pediatrics, Asan Medical Center \\ Children's Hospital, University of \\ Ulsan College of Medicine, Seoul, \\ Korea
}

The hypothalamus plays a key role in the regulation of body weight by balancing the intake of food, energy expenditure, and body fat stores, as evidenced by the fact that most monogenic syndromes of morbid obesity result from mutations in genes expressed in the hypothalamus. Hypothalamic obesity is a result of impairment in the hypothalamic regulatory centers of body weight and energy expenditure, and is caused by structural damage to the hypothalamus, radiotherapy, Prader-Willi syndrome, and mutations in the LEP, LEPR, POMC, MC4R and CART genes. The pathophysiology includes loss of sensitivity to afferent peripheral humoral signals, such as leptin, dysregulated insulin secretion, and impaired activity of the sympathetic nervous system. Dysregulation of $11 \beta$-hydroxysteroid dehydrogenase 1 activity and melatonin may also have a role in the development of hypothalamic obesity. Intervention of this complex entity requires simultaneous targeting of several mechanisms that are deranged in patients with hypothalamic obesity. Despite a great deal of theoretical understanding, effective treatment for hypothalamic obesity has not yet been developed. Therefore, understanding the mechanisms that control food intake and energy homeostasis and pathophysiology of hypothalamic obesity can be the cornerstone of the development of new treatments options. Early identification of patients at-risk can relieve the severity of weight gain by the provision of dietary and behavioral modification, and antiobesity medication. This review summarizes recent advances of the pathophysiology, endocrine characteristics, and treatment strategies of hypothalamic obesity.

Keywords: Hypothalamus, Insulin, Leptin, Obesity

\section{Introduction}

The hypothalamus plays an important role in the regulation of body weight by balancing the intake of food, energy expenditure, and body fat stores. Hypothalamic obesity is thought to result from a disruption of the mechanisms that control satiety and hunger, and to be caused by structural damage to the hypothalamus, radiotherapy or the resection of a brain tumor, and genetic defects in the hypothalamus ${ }^{1)}$. Hypothalamic obesity is evident in as many as $30-50 \%$ of children undergoing surgical treatment for brain tumors, especially craniopharyngiomas and astrocytomas ${ }^{2,3)}$. Craniopharyngioma and its treatment which can take the form of neurosurgery or radiotherapy can cause direct damage to the ventromedial nuclei (VMN) of the hypothalamus, which are critical for appetite regulation and weight homeostasis. As the therapeutic modalities for childhood brain tumors become more effective, and a greater proportion of these patients survive until adulthood, a number of the patients have gained excessive weight. Consequently, the incidence of cardiovascular disease, metabolic syndrome, type 2 diabetes mellitus, nonalcoholic fatty liver disease (NAFLD), and sleep apnea in these patients has increased. However, the weight gain is often intractable, and not responsive to diet or exercise therapy ${ }^{4)}$. Recent studies have shown that the consumption of dietary fats induces the apoptosis of neurons and a reduction of synaptic inputs in the arcuate nucleus (ARC) 
and lateral hypothalamus (LH) in rodents ${ }^{5}$. Therefore, further investigation into the pathophysiology of hypothalamic obesity could enhance our understanding of the mechanisms of weight regulation and obesity and lead to the development of new treatment options. This review summarizes recent advances in the pathophysiology, endocrine characteristics, and treatment strategies of hypothalamic obesity in children and adolescents.

\section{Hypothalamic control of appetite and energy regulation}

The hypothalamus is known to be the master gland of weight equilibrium. It interprets afferent signals from peripheral tissues, and sends efferent signals to expend or store energy. The main hypothalamic areas involved in energy regulation are the medial hypothalamus which consists of the VMN, ARC, and paraventricular nucleus (PVN), and the $\mathrm{LH}^{6)}$. The ARC contains two groups of neurons. The first group of ARC neurons generates orexigenic peptides, such as agouti-related protein and neuropeptide Y (NPY). The second group secretes anorexigenic peptides like proopiomelanocortin (POMC), and cocaine- and amphetamine-related transcript (CART). POMC neurons are a precursor of the anorectic peptide a-melanocyte-stimulating hormone ( $\alpha-\mathrm{MSH})$. The $\alpha$-MSH acts at the melanocorin 4 receptor $(\mathrm{MC} 4 \mathrm{R})$ and reduces appetite and food intake ${ }^{7)}$. The PVN expresses melanocortin receptors 3 and 4 and NPY receptors. It also secretes neuropeptides such as corticotropin-releasing hormone, oxytocin, and vasopressin that have an anorexigenic action ${ }^{8)}$. Afferent signals, including leptin from adipose tissue, insulin from the pancreas, and ghrelin and peptide YY from the gastrointestinal tract affect the anorexigenic center of the hypothalamus. Efferent signals from the PVN and LH in turn stimulate the sympathetic nervous system (SNS) or the vagus nerve through the autonomic nervous system. Efferent signals from these hypothalamic nuclei also include growth hormone-releasing hormone, somatostatin, and thyrotropin-releasing hormone, which control adipose tissue metabolism and the metabolic rate by regulating the secretion of pituitary hormones, such as adrenocorticotropic hormone, $\mathrm{GH}$, and thyroid stimulating hormone ${ }^{6,9)}$.

Additionally, dysregulation of the SNS, insulin hypersecretion through vagus nerve stimulation, and hypercortisolemia by dysregulation of $11 \beta$-hydroxysteroid dehydrogenase 1 (11 $\beta$-HSD1) could influence the development of hypothalamic obesity.

\section{Etiology and pathophysiology of hypothalamic obesity}

Hypothalamic obesity occurs as a consequence of structural damage to the hypothalamus, i.e., brain tumors, inflammation, trauma, neurosurgery, radiation therapy, and cerebral aneurysm (Table 1). Excessive weight gain can develop in one-third of patients who have undergone a resection of space-occupying lesions in the hypothalamic-pituitary region, such as pituitary adenoma, germinoma, craniopharyngioma, and astrocytoma. Several risk factors have been identified as predisposing survivors of childhood brain tumors to the development of obesity: hypothalamic location, high radiation dose, extent of surgery, and tumor histology such as craniopharyngioma and astrocytoma $^{10,11)}$. The presence of other endocrine dysfunctions, especially GH deficiency, also aggravates weight gain ${ }^{12)}$.

Several monogenic obesity syndromes involve genetic defects in the weight-regulating hypothalamic pathways, and even simple obesity can be caused by polymorphisms in these genes ${ }^{13)}$. Understanding of the accompanying hormonal changes in these syndromes helps define the pathophysiology of hypothalamic obesity. Bardet-Biedl syndrome (BBS) is characterized by rod-cone dystrophy, postaxial polydactyly, mental retardation, hypogonadotropic hypogonadism, and renal dysfunction, and is also associated with hypothalamic obesity $^{14)}$. In this syndrome, $52 \%$ of patients are obese and $16 \%$ are morbidly obese ${ }^{14)}$. Rapid-onset obesity with hypoventilation, hypothalamic dysfunction, and autonomic dysregulation (ROHHAD) syndrome is characterized by the remarkable feature of rapid-onset obesity, which begin between two and four years of age, and is accompanied by lateonset hypoventilation, the clinical features of Cushing disease, cortisol deficiency, GH deficiency, central hypothyroidism, hypogonadotropic hypogonadism, and hyperprolactinemia ${ }^{15)}$ The pathophysiology of ROHHAD syndrome has not yet been identified, however, genetic causes are suspected because of the lack of structural damage to the hypothalamus.

Prader-Willi syndrome (PWS) accompanies hypothalamic endocrine dysfunction, which exacerbates weight gain. However, the pathophysiology of the hypothalamic dysfunction in PWS

\begin{tabular}{l} 
Table 1. Structural damages leading to hypothalamic obesity ${ }^{13)}$ \\
\hline Tumor \\
Craniopharyngioma \\
Pituitary macroadenoma \\
Glioma \\
Germinoma \\
Hamartoma \\
Chordoma \\
Ependymoma \\
Meningioma \\
Teratoma \\
Leukemia \\
Langerhans cell histiocytosis \\
Metastasis \\
Inflammatory \\
Sarcoidosis \\
Tuberculosis \\
Arachnioditis \\
Encephalitis \\
Head injury \\
Neurosurgery \\
Radiation \\
Aneurysm
\end{tabular}


seems to be different from the other causes of hypothalamic obesity. The key finding is markedly increased ghrelin levels in the fasting and postprandial state compared to control subjects ${ }^{16-18}$, which contributes to hyperphagia and obesity. In addition, lower fasting and postprandial insulin levels in PWS compared to non-PWS obese subjects have been observed ${ }^{18)}$. Serum leptin levels are high in the patient with PWS and show significantly positive correlations with body weight ${ }^{199}$, and leptin resistance in these patients is similar to that of patients with hypothalamic obesity caused by anatomical damage. In a recent study, a microdeletion of the noncoding HBII- 85 small nuclear RNAs (snoRNAs) caused clinical characteristics similar to $\mathrm{PWS}^{20)}$. However, the HBII-85 snoRNA cluster has as-yetunidentified targets in the brain, which affect appetite, and neuroendocrine and other brain functions that lead to PWSassociated phenotypes.

Many psychotropic drugs, including antidepressants, mood stabilizers, antipsychotic drugs, and antiepileptic drugs can lead to severe weight gain. The mechanism of weight gain is related to a complex and highly redundant network of neurotransmitters, neuromodulators, cytokines, and hormones which are involved in appetite control ${ }^{21}$. Some of these drugs increase peripheral insulin resistance or insulin secretion from the pancreatic $\beta$-cells ${ }^{22}$. Clozapine and olanzapine, as well as other atypical antipsychotic medications, are associated with more weight gain than classical neuroleptics. In these drug-treated patients, hyperphagia is significantly increased ${ }^{23)}$, and hyperleptinemia and hyperinsulinemia manifest ${ }^{24)}$.

\section{Clinical and endocrinological features of hypothalamic obesity}

Patients with hypothalamic obesity show extreme hyperphagia, i.e., abnormal food-seeking behavior, such as foraging for food, stealing food or stealing money for food ${ }^{25)}$. These behaviors resemble those seen in patients with PWS or MC4R deficiencies ${ }^{26,277}$. Patients with hypothalamic obesity have an increased prevalence of impaired glucose tolerance, type 2 diabetes mellitus, hypertension, sleep apnea, NAFLD, and cardiovascular risk ${ }^{4}$.

Many patients with craniopharyngioma with hypothalamic involvement, leptin deficiency, BBS, and PWS show reduced physical activity. The most prominent and concerning complaints in patients undergoing surgical treatment for brain tumors are persistent fatigue and lack of energy despite hormonal replacement therapy ${ }^{28)}$. Patients with hypothalamic obesity manifest another dysfunction of the hypothalamus, resulting in somnolence, behavioral changes, and hypopituitarism ${ }^{28,29}$. Monogenic obesity in some patients is accompanied by other endocrine dysfunctions, such as hypogonadotropic hypogonadism (leptin deficiency), and GH deficiency and thyrotropin deficiency (leptin receptor deficiency). Hypogonadotropic hypogonadism and GH deficiency also occur in patients with PWS ${ }^{30)}$.

Hypothalamic obesity is associated with several endocrine dysfunctions, such as hyperleptinemia, hyperinsulinemia, reduced SNS tone, dysregulation of $11 \beta-H S D 1$ and melatonin, and a decreased basal metabolic rate.

Leptin, a hormone synthesized in the fat cells, placenta, gastrointestinal tract, and possibly the brain, is primarily involved in the regulation of food intake and energy expenditure by acting as an afferent signal from the peripheral circulatory system via active transport ${ }^{31}$. Leptin inhibits orexigenic pathways mediated by neurons expressing the melanocortin antagonist. Leptin-deficient subjects exhibit intense hyperphagia with food-seeking behaviors ${ }^{322}$. Homozygous mutations in the human $L E P R$ gene result in early-onset morbid obesity, accompanied by hypogonadotropic hypogonadism, GH deficiency, and thyrotropin deficiency ${ }^{333}$. In patients with simple obesity, an increase in plasma leptin levels may not be adequately translated into regulatory signals to control excessive weight gain, suggesting leptin insensitivity. Leptin levels corrected for body mass index (BMI) are higher in patients with hypothalamic obesity than in simple obesity, indicating more severe leptin resistance in hypothalamic obesity ${ }^{34)}$.

The primary defect in hypothalamic obesity is altered neural regulation of the $\beta$-cells resulting in insulin hypersecretion, in contrast to simple obesity where peripheral insulin resistance is the primary defect driving a compensatory $\beta$-cell respons ${ }^{34)}$. Compared to simple obese children, hypothalamic obesity patients have a higher insulin response to glycemic loads ${ }^{34,35}$. However, children with hypothalamic obesity frequently have normal fasting insulin levels ${ }^{31)}$. Another study reported that hypothalamic obesity is associated with metabolic syndrome and cardiovascular morbidity without increased insulin sensitivity ${ }^{36}$. These results suggest that hypothalamic obesity cause insulin hypersecretion without insulin resistance. Several mechanisms contribute to hyperinsulinemia, i.e., pathology in the POMC-MC4R pathway, loss of central insulin signaling, and loss of parasympathetic inhibition. Hypothalamic POMC neurons are critical for controlling homeostatic function ${ }^{37)}$, and subjects with MC4R deficiency have severe hyperinsulinemia due to decreased sensitivity to $a-\mathrm{MSH}^{27)}$. It has been postulated that hyperinsulinemia contributes to growth without GH phenomenon in hypothalamic obesity ${ }^{38,39)}$.

SNS is a key regulator of the metabolic rate of adipose tissue by fat mobilization and thermogenesis. Recent data has shown that hypothalamic obesity patients with craniopharyngioma have decreased urinary homovanillic acid and vanillylmandelic acid, indicating reduced sympathetic tone ${ }^{40)}$. Another study demonstrated the selective impairment of hypoglycemic counterregulatory sympathoadrenal activation in patients who had undergone surgery for craniopharyngioma, and this result supports the view that hypothalamic centers are crucial for the coordination of sympathetic counterregulatory responses during hypoglycemia ${ }^{41}$. As previously mentioned, patients with hypothalamic obesity show high leptin levels and low insulin resistance compared to patients with simple obesity, and these findings may be related to the dysregulation of the signaling pathways in the afferent and efferent arms through the SNS. 
Dysregulation of the SNS in hypothalamic obesity is thought to be involved in the disruption of ARC leading to a reduction in the basal metabolic rate. Leptin has been suggested as one of the endogenous signaling molecules in the CART-mediated sympathetic neural pathway ${ }^{42)}$.

$11 \beta$-HSD 1 converts cortisone to cortisol and is expressed in several organs, such as the liver and adipose tissue. A study showed that the urinary free and conjugate cortisol/cortisone and their metabolites (11-OH/11-oxo) were significantly high in patients with hypothalamic obesity, and this ratio showed a significant correlation with the ratio of visceral fat/ subcutaneous fat ${ }^{43)}$. These results demonstrated enhanced cortisone-to-cortisol conversion in hypothalamic obesity and imply that the hypothalamus conveys a signal to the peripheral circulatory system, which modulates its $11 \beta$-HSD1.

Melatonin, a pineal indoleamine, is secreted during the hours of darkness and influences the circadian rhythm. Since sleep regulation and circadian rhythms are partially mediated by hypothalamic structures, sleep disturbance is shown in patients with childhood craniopharyngioma ${ }^{44)}$. Increased daytime sleepiness is related to decreased nocturnal melatonin levels, and nocturnal melatonin levels have been related to the degree of obesity in patients with craniopharyngioma ${ }^{45}$.

\section{Medical and surgical treatment of hypothalamic obesity}

The treatment of hypothalamic obesity requires an understanding of its pathophysiology. The conventional treatments are a calorie-restricted diet, exercise therapy, or pharmacologic treatment, but there is no effective treatment for hypothalamic obesity. Hyperphagia is difficult to control, and most attempts at behavior modification have proved unsuccessful. Pharmacotherapy focuses on alterations in the efferent pathways, such as sympathomimetics, triiodothyronine, and somatostatin analogue. Given the limited choices and poor results of pharmacotherapy, emerging data support the role of surgical treatments as effective options. There is no consensus regarding optimal weight management strategies, however, the best treatment is prevention.

Since the mechanism of hypothalamic damage decreases the activity of the SNS and reduces basal metabolic rate, sympathomimetics are a good therapeutic option. A study demonstrated that dextroamphetamine sulfate treatment following surgical resection for craniopharyngioma can achieve weight maintenance and improvements in children's activity and attention, however, their insulin levels or caloric intake did not change ${ }^{46)}$. In a study of 12 patients with dextroamphetamine therapy, a stabilization or reduction in weight and improvements in daytime wakefulness and exercise tolerance were evident ${ }^{47}$, while, another study showed that treatment with ephedrine and caffeine appeared to help patients lose or maintain weight ${ }^{48)}$. However, these studies only included a small number of patients. Thus, large cohort studies are needed to evaluate the overall efficacy of these treatments.
The somatostatin analog, octreotide, binds to somatostatin receptor- 5 on the $\beta$-cell membrane, which restricts insulin release. In an open-label pilot study, treatment for six months with octreotide promoted weight loss or stabilization in eight patients with hypothalamic obesity, and this was accompanied by an improvement in glucose tolerance and decreased leptin levels ${ }^{35)}$. A double-blind, placebo-controlled trial of 10 subjects showed that octreotide treatment resulted in insulin suppression, stabilization of weight and BMI, and an improvement in quality of life ${ }^{49)}$.

Thyroid hormones play an important role in the regulation of energy balance, in particular, through the stimulation of the SNS. Deiodinase type II (D2), which is mainly present in the brain, brown fat, placenta, pituitary and muscle, is essential for the generation of T3 in tissue. In brown fat, D2 activity is stimulated by leptin ${ }^{50)}$ and contributes to systemic T3 levels. In three patients with hypothalamic obesity, T3 supplementation promoted weight loss ${ }^{51)}$.

Sibutramine is a nonspecific inhibitor of the presynaptic reuptake of serotonin and norepinephrine. A double-blind, placebo-controlled trial of 21 subjects showed significant weight reduction through the administration of sibutraimine ${ }^{52)}$. However, sibutramine has been withdrawn from the market due to its adverse cardiovascular effects.

Glucagon-like peptide 1 (GLP-1) is a gut-derived incretin that stimulates insulin and suppresses glucagon secretion ${ }^{53)}$. The U.S. Food and Drug Administration approved GLP1 for the treatment of type 2 diabetes in adults. Exenatide, a GLP-1 homologue, resulted in a considerable reduction in body weight in a 17 -year-old boy with severe hypothalamic obesity ${ }^{54)}$. Another observational study sustained for as long as 51 months showed that treatment with GLP-1 analogues promoted substantial weight loss in eight of nine patients with hypothalamic obesity ${ }^{55)}$. However, these were not controlled studies and the number of treated patients was both relatively small and restricted to adolescent and adult patients.

Bariatric surgery remains the most effective treatment for morbid obesity and is indicated for adult patients with significant obesity-related comorbidities. Laparoscopic adjustable gastric banding was performed on four adolescent patients with craniopharyngioma, and resulted in significant weight loss in all four patients ${ }^{56)}$. In a patient with gastric bypass surgery, significant weight loss was also noted and insulin and leptin levels were normalized ${ }^{57)}$.

\section{Conclusions}

Hypothalamic obesity is the result of impairment in the hypothalamic regulatory centers of body weight and energy expenditure, and is caused by structural, functional, and genetic defects of the hypothalamic nuclei, including the VMN, PVN, ARC, and LH. The pathophysiology includes a loss of sensitivity to afferent peripheral humoral signals, hyperleptinemia, hyperinsulinemia, impaired activity of the SNS, increased 
$11 \beta$-HSD 1 activity, and a low basal metabolic rate. The mechanisms of hypothalamic obesity that disrupt the regulation of appetite and body weight following structural damage in the hypothalamus and monogenic obesity syndrome have been investigated. Despite a great deal of theoretical understanding, an effective treatment for hypothalamic obesity has not yet been developed. To determine a successful therapeutic scheme, both an improved understanding of the underlying pathophysiologies of hypothalamic obesity and multicenter trials to examine the efficacy of novel interventions are needed.

\section{Conflict of interest}

No potential conflict of interest relevant to this article was reported.

\section{References}

1. Daousi C, Dunn AJ, Foy PM, MacFarlane IA, Pinkney JH. Endocrine and neuroanatomic features associated with weight gain and obesity in adult patients with hypothalamic damage. Am J Med 2005;118:45-50.

2. Rutter MM, Rose SR. Long-term endocrine sequelae of childhood cancer. Curr Opin Pediatr 2007;19:480-7.

3. Geffner M, Lundberg M, Koltowska-Haggstrom M, Abs R, Verhelst J, Erfurth EM, et al. Changes in height, weight, and body mass index in children with craniopharyngioma after three years of growth hormone therapy: analysis of KIGS (Pfizer International Growth Database). J Clin Endocrinol Metab 2004;89:5435-40.

4. Deepak D, Furlong NJ, Wilding JP, MacFarlane IA. Cardiovascular disease, hypertension, dyslipidaemia and obesity in patients with hypothalamic-pituitary disease. Postgrad Med J 2007;83:277-80.

5. Moraes JC, Coope A, Morari J, Cintra DE, Roman EA, Pauli JR, et al. High-fat diet induces apoptosis of hypothalamic neurons. PLoS One 2009;4:e5045.

6. Hochberg I, Hochberg Z. Hypothalamic obesity. Endocr Dev 2010;17:185-96.

7. Coll AP, Farooqi IS, Challis BG, Yeo GS, O'Rahilly S. Proopiomelanocortin and energy balance: insights from human and murine genetics. J Clin Endocrinol Metab 2004;89:2557-62.

8. Lu XY, Barsh GS, Akil H, Watson SJ. Interaction between alpha-melanocyte-stimulating hormone and corticotropinreleasing hormone in the regulation of feeding and hypothalamo-pituitary-adrenal responses. J Neurosci 2003;23:7863-72.

9. Woods SC, D'Alessio DA. Central control of body weight and appetite. J Clin Endocrinol Metab 2008;93(11 Suppl 1):S37-50.

10. Lustig RH, Post SR, Srivannaboon K, Rose SR, Danish RK, Burghen GA, et al. Risk factors for the development of obesity in children surviving brain tumors. J Clin
Endocrinol Metab 2003;88:611-6.

11. Muller HL, Emser A, Faldum A, Bruhnken G, EtavardGorris N, Gebhardt U, et al. Longitudinal study on growth and body mass index before and after diagnosis of childhood craniopharyngioma. J Clin Endocrinol Metab 2004;89:3298-305.

12. Luque RM, Kineman RD. Impact of obesity on the growth hormone axis: evidence for a direct inhibitory effect of hyperinsulinemia on pituitary function. Endocrinology 2006;147:2754-63.

13. Hochberg I, Hochberg Z. Expanding the definition of hypothalamic obesity. Obes Rev 2010;11:709-21.

14. Beales PL, Elcioglu N, Woolf AS, Parker D, Flinter FA. New criteria for improved diagnosis of Bardet-Biedl syndrome: results of a population survey. J Med Genet 1999;36:437-46.

15. Bougneres P, Pantalone L, Linglart A, Rothenbuhler A, Le Stunff C. Endocrine manifestations of the rapid-onset obesity with hypoventilation, hypothalamic, autonomic dysregulation, and neural tumor syndrome in childhood. J Clin Endocrinol Metab 2008;93:3971-80.

16. Haqq AM, Farooqi IS, O'Rahilly S, Stadler DD, Rosenfeld RG, Pratt KL, et al. Serum ghrelin levels are inversely correlated with body mass index, age, and insulin concentrations in normal children and are markedly increased in Prader-Willi syndrome. J Clin Endocrinol Metab 2003;88:174-8.

17. Kanumakala S, Greaves R, Pedreira CC, Donath S, Warne GL, Zacharin MR, et al. Fasting ghrelin levels are not elevated in children with hypothalamic obesity. J Clin Endocrinol Metab 2005;90:2691-5.

18. Goldstone AP, Patterson M, Kalingag N, Ghatei MA, Brynes AE, Bloom SR, et al. Fasting and postprandial hyperghrelinemia in Prader-Willi syndrome is partially explained by hypoinsulinemia, and is not due to peptide YY3-36 deficiency or seen in hypothalamic obesity due to craniopharyngioma. J Clin Endocrinol Metab 2005;90:2681-90.

19. Hoybye C, Barkeling B, Espelund U, Petersson M, Thoren M. Peptides associated with hyperphagia in adults with Prader-Willi syndrome before and during GH treatment. Growth Horm IGF Res 2003;13:322-7.

20. Sahoo T, del Gaudio D, German JR, Shinawi M, Peters SU, Person RE, et al. Prader-Willi phenotype caused by paternal deficiency for the HBII-85 C/D box small nucleolar RNA cluster. Nat Genet 2008;40:719-21.

21. Zimmermann U, Kraus T, Himmerich H, Schuld A, Pollmacher T. Epidemiology, implications and mechanisms underlying drug-induced weight gain in psychiatric patients. J Psychiatr Res 2003;37:193-220.

22. Bergman RN, Ader M. Atypical antipsychotics and glucose homeostasis. J Clin Psychiatry 2005;66:504-14.

23. Gothelf D, Falk B, Singer P, Kairi M, Phillip M, Zigel L, et al. Weight gain associated with increased food intake and low habitual activity levels in male adolescent schizophrenic inpatients treated with olanzapine. Am J Psychiatry 
2002;159:1055-7.

24. Melkersson KI, Hulting AL, Brismar KE. Elevated levels of insulin, leptin, and blood lipids in olanzapine-treated patients with schizophrenia or related psychoses. J Clin Psychiatry 2000;61:742-9.

25. Skorzewska A, Lal S, Waserman J, Guyda H. Abnormal foodseeking behavior after surgery for craniopharyngioma. Neuropsychobiology 1989;21:17-20.

26. Goldstone AP. Prader-Willi syndrome: advances in genetics, pathophysiology and treatment. Trends Endocrinol Metab 2004;15:12-20.

27. Farooqi IS, Keogh JM, Yeo GS, Lank EJ, Cheetham T, O'Rahilly S. Clinical spectrum of obesity and mutations in the melanocortin 4 receptor gene. N Engl J Med 2003;348:1085-95.

28. Dekkers OM, Biermasz NR, Smit JW, Groot LE, Roelfsema F, Romijn JA, et al. Quality of life in treated adult craniopharyngioma patients. Eur J Endocrinol 2006;154:483-9.

29. Snow A, Gozal E, Malhotra A, Tiosano D, Perlman R, Vega C, et al. Severe hypersomnolence after pituitary/hypothalamic surgery in adolescents: clinical characteristics and potential mechanisms. Pediatrics 2002;110:e74.

30. Bittel DC, Butler MG. Prader-Willi syndrome: clinical genetics, cytogenetics and molecular biology. Expert Rev Mol Med 2005;7:1-20.

31. Shaikh MG, Grundy RG, Kirk JM. Hyperleptinaemia rather than fasting hyperinsulinaemia is associated with obesity following hypothalamic damage in children. Eur J Endocrinol 2008;159:791-7.

32. Farooqi IS, O'Rahilly S. Leptin: a pivotal regulator of human energy homeostasis. Am J Clin Nutr 2009;89:980S-984S.

33. Clément K, Vaisse C, Lahlou N, Cabrol S, Pelloux V, Cassuto D, et al. A mutation in the human leptin receptor gene causes obesity and pituitary dysfunction. Nature 1998;392:398-401.

34. Guran T, Turan S, Bereket A, Akcay T, Unluguzel G, Bas F, et al. The role of leptin, soluble leptin receptor, resistin, and insulin secretory dynamics in the pathogenesis of hypothalamic obesity in children. Eur J Pediatr 2009; 168:1043-8.

35. Lustig RH, Rose SR, Burghen GA, Velasquez-Mieyer P, Broome DC, Smith K, et al. Hypothalamic obesity caused by cranial insult in children: altered glucose and insulin dynamics and reversal by a somatostatin agonist. J Pediatr 1999;135(2 Pt 1):162-8.

36. Srinivasan S, Ogle GD, Garnett SP, Briody JN, Lee JW, Cowell CT. Features of the metabolic syndrome after childhood craniopharyngioma. J Clin Endocrinol Metab 2004;89:81-6.

37. Parton LE, Ye CP, Coppari R, Enriori PJ, Choi B, Zhang $\mathrm{CY}$, et al. Glucose sensing by POMC neurons regulates glucose homeostasis and is impaired in obesity. Nature 2007;449:228-32.

38. Phillip M, Moran O, Lazar L. Growth without growth hormone. J Pediatr Endocrinol Metab 2002;15 Suppl 5:1267-72.

39. Bucher H, Zapf J, Torresani T, Prader A, Froesch ER, Illig R. Insulin-like growth factors I and II, prolactin, and insulin in 19 growth hormone-deficient children with excessive, normal, or decreased longitudinal growth after operation for craniopharyngioma. N Engl J Med 1983;309:1142-6.

40. Roth CL, Hunneman DH, Gebhardt U, Stoffel-Wagner B, Reinehr T, Muller HL. Reduced sympathetic metabolites in urine of obese patients with craniopharyngioma. Pediatr Res 2007;61:496-501.

41. Schofl C, Schleth A, Berger D, Terkamp C, von zur Muhlen A, Brabant G. Sympathoadrenal counterregulation in patients with hypothalamic craniopharyngioma. J Clin Endocrinol Metab 2002;87:624-9.

42. Dun SL, Brailoiu GC, Yang J, Chang JK, Dun NJ. Cocaineand amphetamine-regulated transcript peptide and sympatho-adrenal axis. Peptides 2006;27:1949-55.

43. Tiosano D, Eisentein I, Militianu D, Chrousos GP, Hochberg Z. 11 beta-Hydroxysteroid dehydrogenase activity in hypothalamic obesity. J Clin Endocrinol Metab 2003;88:379-84.

44. Manley PE, McKendrick K, McGillicudy M, Chi SN, Kieran MW, Cohen LE, et al. Sleep dysfunction in long term survivors of craniopharyngioma. J Neurooncol 2012;108:543-9.

45. Muller HL, Handwerker G, Wollny B, Faldum A, Sorensen $\mathrm{N}$. Melatonin secretion and increased daytime sleepiness in childhood craniopharyngioma patients. J Clin Endocrinol Metab 2002;87:3993-6.

46. Mason PW, Krawiecki N, Meacham LR. The use of dextroamphetamine to treat obesity and hyperphagia in children treated for craniopharyngioma. Arch Pediatr Adolesc Med 2002;156:887-92.

47. Ismail D, O'Connell MA, Zacharin MR. Dexamphetamine use for management of obesity and hypersomnolence following hypothalamic injury. J Pediatr Endocrinol Metab 2006;19:129-34.

48. Greenway FL, Bray GA. Treatment of hypothalamic obesity with caffeine and ephedrine. Endocr Pract 2008; 14:697703 .

49. Lustig RH, Hinds PS, Ringwald-Smith K, Christensen RK, Kaste SC, Schreiber RE, et al. Octreotide therapy of pediatric hypothalamic obesity: a double-blind, placebocontrolled trial. J Clin Endocrinol Metab 2003;88:2586-92.

50. Cettour-Rose P, Burger AG, Meier CA, Visser TJ, RohnerJeanrenaud F. Central stimulatory effect of leptin on T3 production is mediated by brown adipose tissue type II deiodinase. Am J Physiol Endocrinol Metab 2002;283:E980-7.

51. Fernandes JK, Klein MJ, Ater JL, Kuttesch JF, VassilopoulouSellin R. Triiodothyronine supplementation for hypothalamic obesity. Metabolism 2002;51:1381-3.

52. Danielsson P, Janson A, Norgren S, Marcus C. Impact sibutramine therapy in children with hypothalamic obesity 
or obesity with aggravating syndromes. J Clin Endocrinol Metab 2007;92:4101-6.

53. Drucker DJ, Nauck MA. The incretin system: glucagonlike peptide-1 receptor agonists and dipeptidyl peptidase- 4 inhibitors in type 2 diabetes. Lancet 2006;368:1696-705.

54. Simmons JH, Shoemaker AH, Roth CL. Treatment with glucagon-like Peptide- 1 agonist exendin- 4 in a patient with hypothalamic obesity secondary to intracranial tumor. Horm Res Paediatr 2012;78:54-8.

55. Zoicas F, Droste M, Mayr B, Buchfelder M, Schofl C. GLP1 analogues as a new treatment option for hypothalamic obesity in adults: report of nine cases. Eur J Endocrinol 2013;168:699-706.

56. Muller HL, Gebhardt U, Wessel V, Schroder S, Kolb R, Sorensen N, et al. First experiences with laparoscopic adjustable gastric banding (LAGB) in the treatment of patients with childhood craniopharyngioma and morbid obesity. Klin Padiatr 2007;219:323-5.

57. Inge TH, Pfluger P, Zeller M, Rose SR, Burget L, Sundararajan $S$, et al. Gastric bypass surgery for treatment of hypothalamic obesity after craniopharyngioma therapy. Nat Clin Pract Endocrinol Metab 2007;3:606-9. 